\title{
Performance Variation of Ferrite Magnet PMBLDC Motor with Temperature.
}

\author{
Fasil, Muhammed; Mijatovic, Nenad; Jensen, Bogi Bech; Holbøll, Joachim
}

Published in:

IEEE Transactions on Magnetics

Link to article, DOI:

10.1109/TMAG.2015.2456854

Publication date:

2015

Document Version

Peer reviewed version

Link back to DTU Orbit

Citation (APA):

Fasil, M., Mijatovic, N., Jensen, B. B., \& Holbøll, J. (2015). Performance Variation of Ferrite Magnet PMBLDC Motor with Temperature. IEEE Transactions on Magnetics, 51(12), [8115106 ].

https://doi.org/10.1109/TMAG.2015.2456854

\section{General rights}

Copyright and moral rights for the publications made accessible in the public portal are retained by the authors and/or other copyright owners and it is a condition of accessing publications that users recognise and abide by the legal requirements associated with these rights.

- Users may download and print one copy of any publication from the public portal for the purpose of private study or research.

- You may not further distribute the material or use it for any profit-making activity or commercial gain

- You may freely distribute the URL identifying the publication in the public portal 


\title{
Performance Variation of Ferrite Magnet PMBLDC Motor with Temperature
}

\author{
Muhammed Fasil ${ }^{1}$, Nenad Mijatovic ${ }^{1}$, Bogi Bech Jensen ${ }^{2}$ and Joachim Holboll ${ }^{1}$ \\ ${ }^{1}$ Department of Electrical Engineering, Technical University of Denmark, Kgs. Lyngby, 2800, Denmark \\ ${ }^{2}$ Department of Science and Technology, University of the Faroe Islands, Torshavn, FO-100, Faroe Islands
}

\begin{abstract}
The price fluctuations of rare earth metals and the uncertainty in their availability has generated an increased interest in ferrite magnet machines. The influence of temperature on BH characteristics of the ferrite magnet differ considerably from that of the rare earth magnet and hence, requires a different approach when deciding their operating point. In this work, laboratory measured BH curves of a ferrite magnet are used for estimating the possibility of demagnetization in a segmented axial torus (SAT) permanent magnet brushless DC (PMBLDC) motor. The BH characteristics for different temperatures have been used to study the performance variation of the ferrite magnet SAT PMBLDC motor with temperature. A detailed analysis is carried out to ensure that, the designed ferrite magnet motor is capable of delivering the specified torque throughout the operating speed, without any irreversible demagnetization of magnets. It has been shown that the ferrite magnet PMBLDC motor operation is influenced by the magnet temperature and the maximum motor speed for a given load torque decreases as the magnet temperature drops.
\end{abstract}

Index Terms-Demagnetization, ferrites, permanent magnets, brushless Machines, permanent magnet machines.

\section{INTRODUCTION}

$\mathbf{I}$ $\mathrm{N}$ recent years, there has been an uncertainty in the availability and the price of rare earth (RE) metals used in high energy magnets [1]. This sets stage for renewed interest in the research of ferrite magnet machines [2]-[6] as ferrites are commonly available. The main challenges in substituting the RE magnet with the ferrite are its low remanence $\left(B_{r}\right)$ and coercivity $\left(H_{c}\right)$. Low $B_{r}$ implies a lower magnetic loading and low $H_{c}$ imparts restriction on the maximum electric loading to prevent demagnetization of the magnet, thus limiting the power density of the ferrite magnet machines. Most of solutions proposed to address this limitation involve placing more magnets in rotor to enhance the air gap flux density [7], [8].

Different aspects of magnet in operation such as reversible and irreversible demagnetization as a result of armature reaction and temperature induced operating point shift on the performance of PM machine have been researched extensively for RE magnets [9]-[12]. In most of these situations, ferrite magnets behave different from RE magnets, because the coercivity of ferrite magnets increase with temperature; in other words, ferrite magnets have a positive temperature coefficient and RE magnets have a negative temperature coefficient for coercivity. The remanence of both magnets decrease with temperature. Moreover, the knee point in demagnetization characteristics appears at low temperature for ferrite magnets and at higher temperature for RE magnets. In applications such as direct drive hub motors, heat from magnets are dissipated rapidly to the surrounding because of their positioning in outer casing and therefore, the possibility of high temperature demagnetization when using RE magnets are less. In contrast, for ferrite magnets used in a similar

Corresponding author: N. Mijatovic (email: nm@elektro.dtu.dk) motor configuration, the inrush current at start can be seen as critical aspect from the magnet perspective, especially at low ambient temperatures, where the risk of demagnetisation is the highest.

Though the design of ferrite magnet machines is discussed extensively in literature [2]-[6], [8], [13], [14]; the performance variation of ferrite magnet PM brushless DC (PMBLDC) motors with temperature has not been examined in detail. Also, there is a lack of systematic approach presented for identifying the leeway for armature reaction with respect to irreversible demagnetization. The work presented in [15] discusses the effect of temperature on torque profile of a ferrite PMBLDC motor with the help of finite element (FE) electromagnetic and thermal model. In [8], the authors described a possible demagnetization due to load line intersecting beyond the knee point of a ferrite magnet at low temperature. In [16], the authors used the flux density distribution in magnets to estimate the level of demagnetization in a PM synchronous generator and also calculated the performance variation with temperature. In [6], the authors used $\mathrm{BH}$ curve of ferrite magnet corresponding to the lowest operating temperature to ensure that the field weakening operation is not causing any irreversible demagnetization in a PM synchronous motor. However, authors did not evaluate the performance variation with temperature. In [17], the authors used manufacturer supplied temperature coefficient of $B_{r}$ and $H_{c}$ of ferrite magnet to evaluate the performance of a line-start PM machine for different operating temperatures.

This paper uses laboratory measured $\mathrm{BH}$ characteristics of a ferrite magnet to evaluate the margin of safety to irreversible demagnetization in a segmented axial torus (SAT) PMBLDC motor. In addition, BH characteristics of the ferrite magnet for different temperatures have been used to study the performance variation of the SAT PMBLDC motor with temperature. 
TABLE I

PROPERTIES OF FERRITE MAGNET (GRADE:Y33BH) AS PER PRODUCT DATA SHEET

\begin{tabular}{lllll}
\hline \hline & & & $\begin{array}{l}\text { Reversible } \\
\text { coefficient }\end{array}$ & temperature \\
\hline$B H_{\text {max }}$ & $B_{r}$ & $H_{c}$ & $\% B_{r}$ & $\% H_{c}$ \\
$\left(\mathrm{~kJ} \mathrm{~m}^{-3}\right)$ & $(\mathrm{T})$ & $\left(\mathrm{kA} \mathrm{m}^{-1}\right)$ & $\left(\%{ }^{\circ} \mathrm{C}^{-1}\right)$ & $\left(\%{ }^{\circ} \mathrm{C}^{-1}\right)$ \\
\hline $33.25 \pm 1.75$ & $0.42 \pm 0.1$ & $247.5 \pm 12.5$ & -0.2 & +0.3 \\
\hline \hline
\end{tabular}

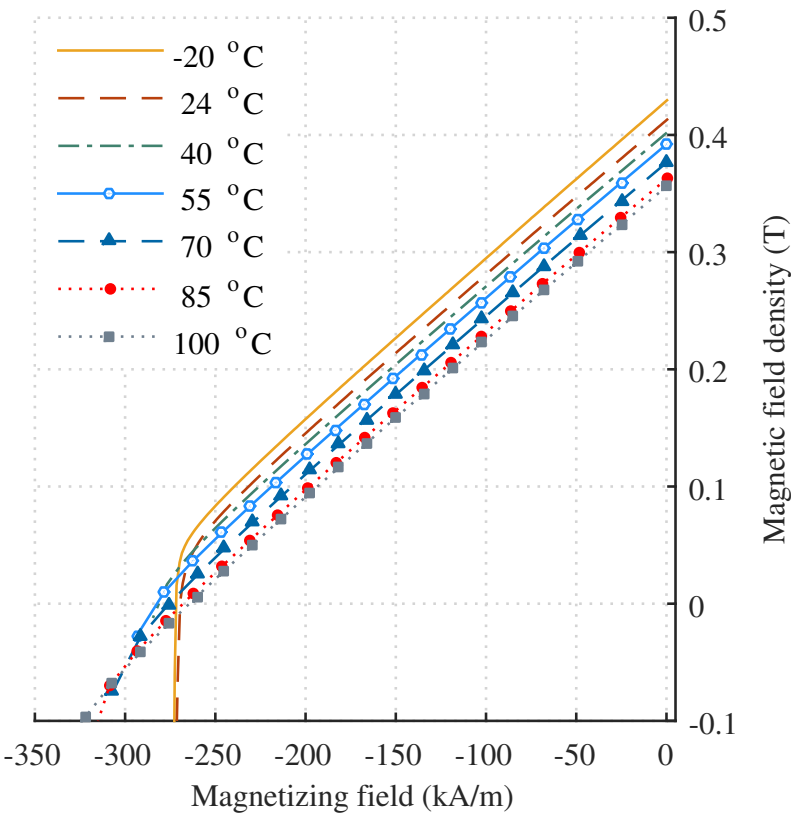

Fig. 1. Measured demagnetization characteristics of the ferrite magnet for different temperatures

\section{MEASURED BH CHARACTERISTICS OF FERRITE MAGNET}

This study has been carried out using a commercially available ferrite magnet and the specification from the product data sheet is shown in Table I. The BH characteristics of the ferrite magnet have been measured for temperatures starting from $-20^{\circ} \mathrm{C}$ to $100^{\circ} \mathrm{C}$. The second quadrant of the characteristics are shown in Fig.1 and each data point is the average value of measurements on five samples. Each curve in Fig.1, corresponding to a temperature, is traced from three hundred to five hundred data points. The only unexpected behaviour observed is corresponding to the room temperature $\left(24^{\circ} \mathrm{C}\right)$ measurements and the curve is found to have knee point earlier than that of $-20^{\circ} \mathrm{C}$ measurements. The second quadrant knee point exists for all temperatures below $70^{\circ} \mathrm{C}$.

With regard to PM machine design, the critical value of demagnetizing field that the magnet can be exposed to without any permanent loss in remanence can be found from the variation of differential permeability. Differential permeability is defined as the slop $(d B / d H)$ of BH curve [18]. Differential permeability of the ferrite magnet material is plotted against the magnetizing field for different temperatures in Fig.2. It is clear from the figure that, the $d B / d H$ remains constant until $250 \mathrm{kA} \mathrm{m}^{-1}$ and its values at lower temperatures are changing

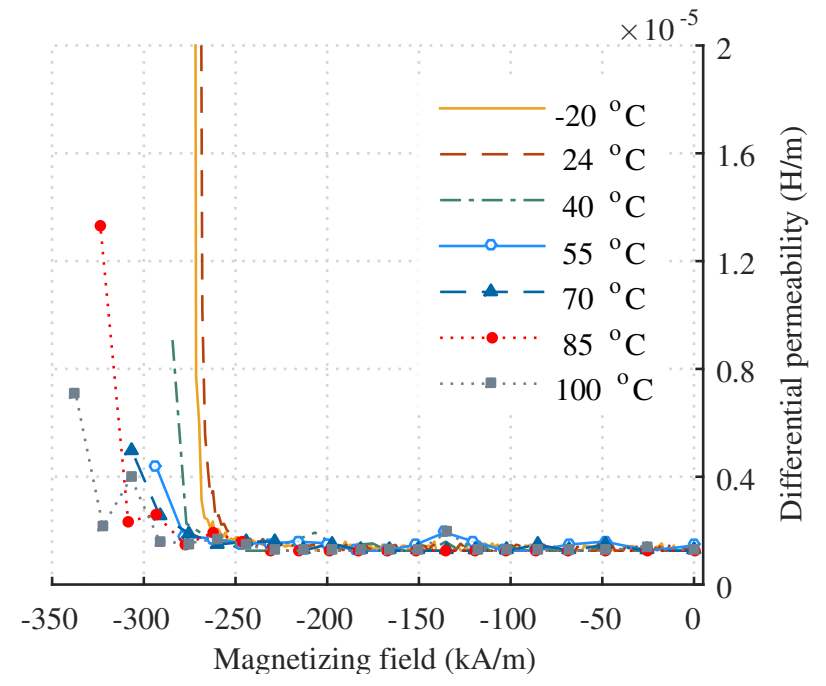

Fig. 2. Differential permeability variation with magnetizing field of the ferrite magnet

initially. Therefore, it can be concluded that, the ferrite magnet used in this study can safely withstand a demagnetizing field or an armature reaction field up to $250 \mathrm{kA} \mathrm{m}^{-1}$.

\section{SEgmented AXIAL TORUS PERMANENT MAGNET BRUSHLESS DC MOTOR}

A SAT PMBLDC motor with ferrite magnet as rotor poles is designed to study the extent of demagnetization under severe armature reaction. The schematic of SAT PMBLDC motor is shown in Fig.3. The SAT motor topology [19]-[21] is a variation of torus slotted north-south (NS) axial flux motor (AFM) topology and has no stator yoke. The magnetically separated teeth can be wound separately before assembly and this ensures high fill factor and short end turn resulting in an efficiency improvement [22]. This add to improved torque density that comes with AFM topology [21]. A pole/slot combination of $P=N s \pm 2$ has been selected to reduce the cogging torque [23]. In addition, a single-layer winding is opted as they are more suitable for BLDC motor operation [23]. The specification and main geometrical dimensions of the motor are listed in Table II. The motor will be used in an electric two-wheeler with maximum speed of $32 \mathrm{~km} \mathrm{~h}^{-1}$. In order to attain the maximum speed of vehicle, the motor should produce a torque of $12 \mathrm{Nm}$ at $330 \mathrm{rpm}$.

\section{ESTIMATION OF DEMAGNETIZATION LEVEL OF FERRITE MAGNET IN OPERATING CONDITION}

As explained in earlier sections, the ferrite magnet is more susceptible to demagnetization at lower temperatures and for this reason, the $\mathrm{BH}$ curve of ferrite magnet at $-20^{\circ} \mathrm{C}$ is used for demagnetization study. The 3D FE static analysis is carried out for two values of peak armature currents $20 \mathrm{~A}$ and $200 \mathrm{~A}$, corresponding to the full load and ten times the full load respectively. In [10], the authors proved that both antiparallel and perpendicular field components to the direction of magnetization are necessary to accurately estimate the level of demagnetization. Therefore, $|H|$ and not $|B|$ field distribution is 


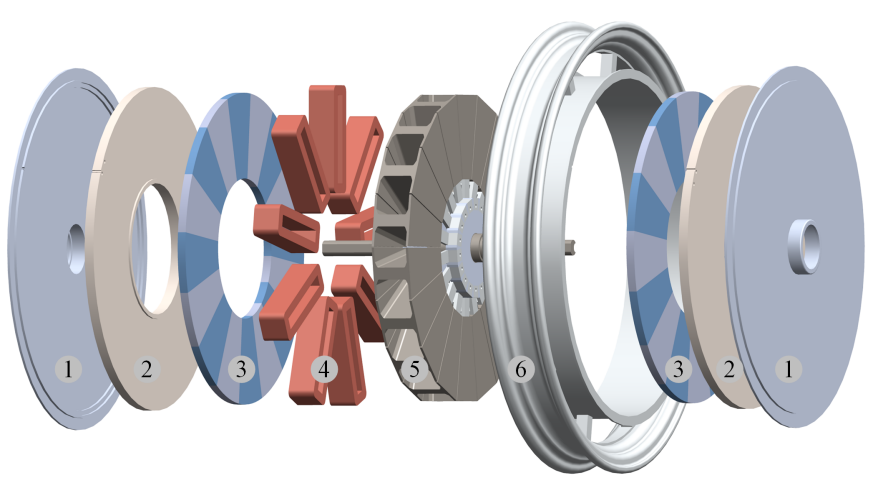

Fig. 3. Schematic of ferrite magnet SAT PMBLDC motor (1. end cover, 2. rotor yoke, 3. magnets, 4. stator winding, 5. stator core and 6. wheel rim).

TABLE II

THE SPECIFICATION AND GEOMETRICAL DIMENSIONS OF FERRITE MAGNET SAT PMBLDC MOTOR

\begin{tabular}{lc}
\hline \hline Parameter & Value \\
\hline The rated voltage & $48 \mathrm{~V}$ \\
The rated power output & $700 \mathrm{~W}$ \\
The rated torque & $20 \mathrm{~N} \mathrm{~m}$ \\
Outer diameter of the motor & $275 \mathrm{~mm}$ \\
Diameter ratio & 0.45 \\
Axial length of the motor & $65.5 \mathrm{~mm}$ \\
Number of poles & 16 \\
Number of slots & 18 \\
Gross slot fill factor & 0.5 \\
Thickness of magnet poles & $7.5 \mathrm{~mm}$ \\
Length of air gap & $0.4 \mathrm{~mm}$ \\
Number of turns per coil & 30 \\
Diameter of a coil turn & $2.68 \mathrm{~mm}$ \\
\hline \hline
\end{tabular}

used in this study. Further, in [24], [25], the authors concluded that the edges and area of permanent magnet exposed to air gap are more susceptible to demagnetization than the inner volume. The demagnetizing field acting on the entire magnet disc is shown in the part (a) of Fig.4 and 5 and the field on a single pole is shown in the part (b) of the same figures. At ten times the rated current, $48 \%$ of magnet volume is experiencing a demagnetizing field value more than $250 \mathrm{kA} \mathrm{m}^{-1}$ and hence nearly half of the magnet disc will be demagnetized. It is clear from figures that at rated current levels only a small volume of magnet located in inter polar region will experience $|H|$ field approaching critical value of $250 \mathrm{kA} \mathrm{m}^{-1}$ for the presented design.

\section{Performance Variation of PMBLDC MOtor With TEMPERATURE}

Besides the shift in knee point, the remanence also varies with temperature for the ferrite magnet as shown in Fig.1. The $B_{r}$ diminishes by more than $10 \%$ when temperature rises from $-20^{\circ} \mathrm{C}$ (the lowest ambient temperature considered) to a steady state magnet temperature under load (assumed to be between 55 to $70^{\circ} \mathrm{C}$ ), and this variation will have an impact on the motor performance. A series of static FE analysis is carried out to find the flux linkage of a phase as a function of rotor

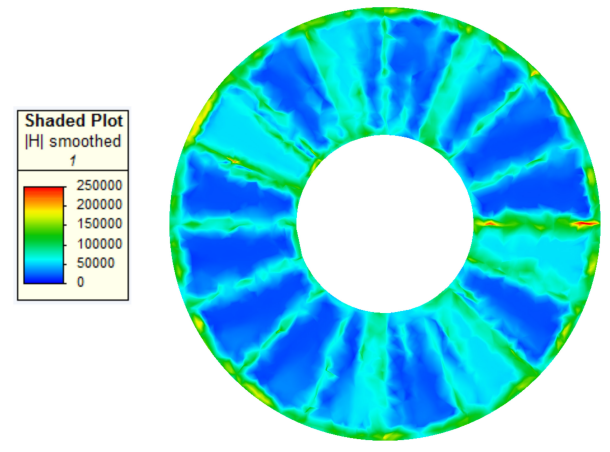

(a)

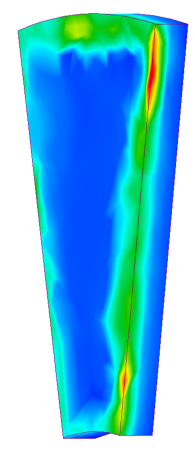

(b)

Fig. 4. Demagnetizing field distribution for an armature current of $20 \mathrm{~A}$ in (a) 16-pole disc and (b) a pole

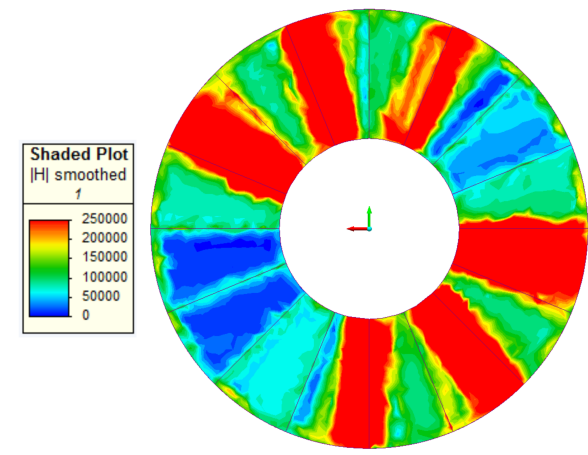

(a)

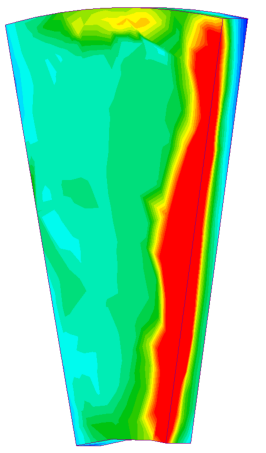

(b)
Fig. 5. Demagnetizing field distribution for an armature current of $200 \mathrm{~A}$ in (a) 16-pole disc and (b) a pole

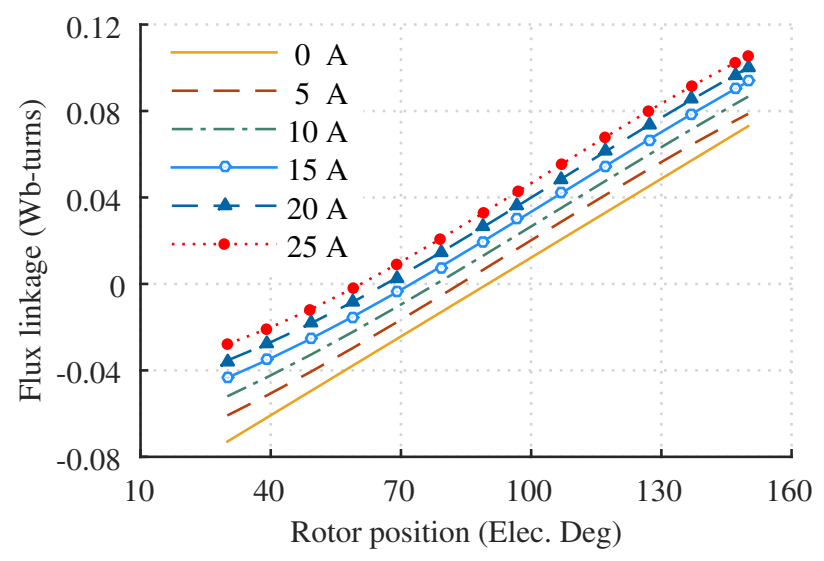

Fig. 6. The variation of flux linkage of a phase with rotor position for different armature currents at a magnet temperature of $-20^{\circ} \mathrm{C}$

position and armature current and results are shown in Fig.6 for a magnet temperature of $-20^{\circ} \mathrm{C}$. As the rotor rotates, flux linkage variations will induce an EMF in the winding and the instantaneous EMF induced per phase $\left(e_{p h}\right)$ can be calculated as

$$
e_{p h}=\frac{d \psi}{d t}=\frac{d \psi}{d \theta} \times \frac{d \theta}{d t}=\psi^{\prime} \times \omega
$$

where, $\psi$ is the flux linkage per phase, $\theta$ is the rotor position and $\omega$ is the angular velocity. The variation of $\psi^{\prime}$ with rotor 


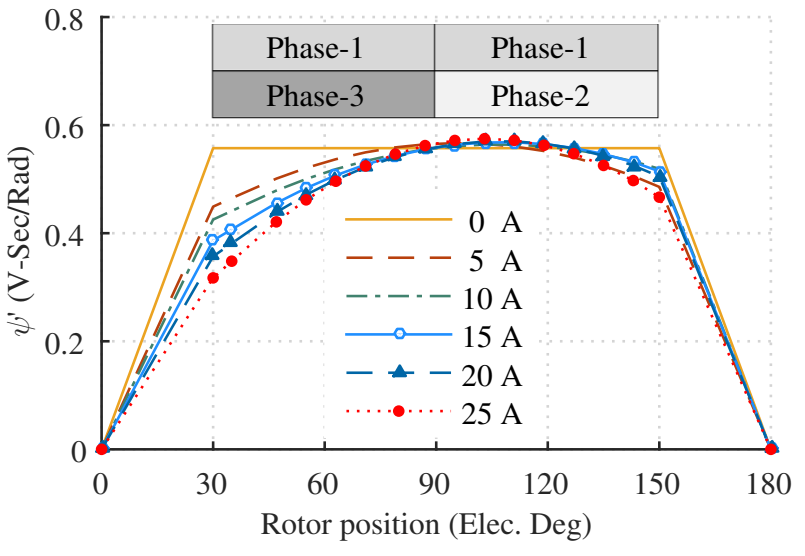

Fig. 7. The variation of $\psi^{\prime}$ with rotor position for different armature currents at a magnet temperature of $-20^{\circ} \mathrm{C}$

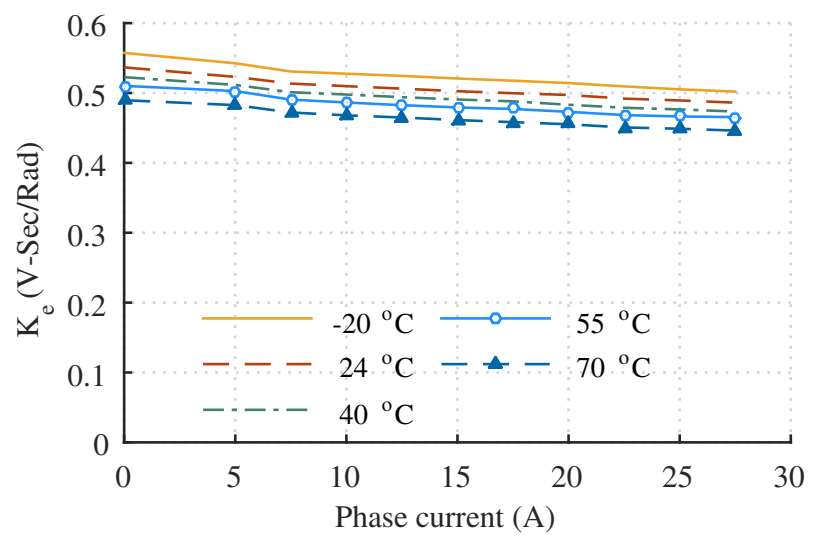

Fig. 8. The variation of the average EMF constant with armature current for different magnet temperatures

position for different armature current is shown in Fig.7. In three-phase PMBLDC motor, only two phases conduct at the same time. Therefore, phase- 1 and phase- 3 conduct for 30 to 90 elec. Deg and phase- 1 and phase- 2 conducts for 90 to 150 elec. Deg as highlighted in Fig.7. The average EMF generated per phase of a PMBLDC motor $\left(E_{p h}\right)$ can be expressed as

$$
E_{p h}=K_{e} \times \omega
$$

where, $K_{e}$ is the EMF constant of a PMBLDC motor. The EMF constant can be derived from the flux linkage variation by comparing (1) and (2) as

$$
K_{e}=\operatorname{mean}\left(\psi^{\prime}\right)
$$

The variation of EMF constant with armature current for different temperature, plotted in Fig.8, shows the effect temperature on $K_{e}$.

A dynamic model of three-phase PMBLDC motor is developed based on models presented in [26]-[29]. The model uses a 3D look-up table of EMF constants as a function of rotor position and armature current to calculate the rotational EMF at a magnet temperature. The phase inductances obtained from the FE model of the motor is included in the model, to account for the effect of transformer EMF. The model neglects the temperature variation of winding resistance as the maximum

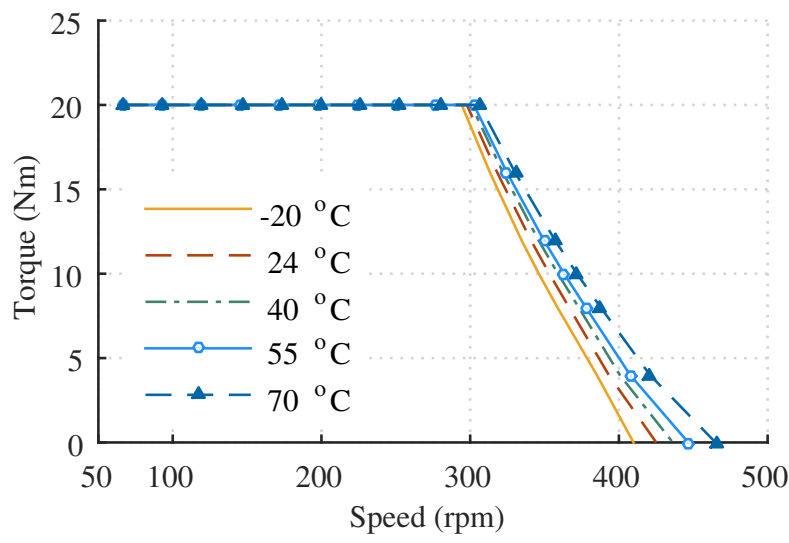

Fig. 9. Torque delivered at shaft vs. speed curves of the ferrite magnet PMBLDC motor for different magnet temperatures

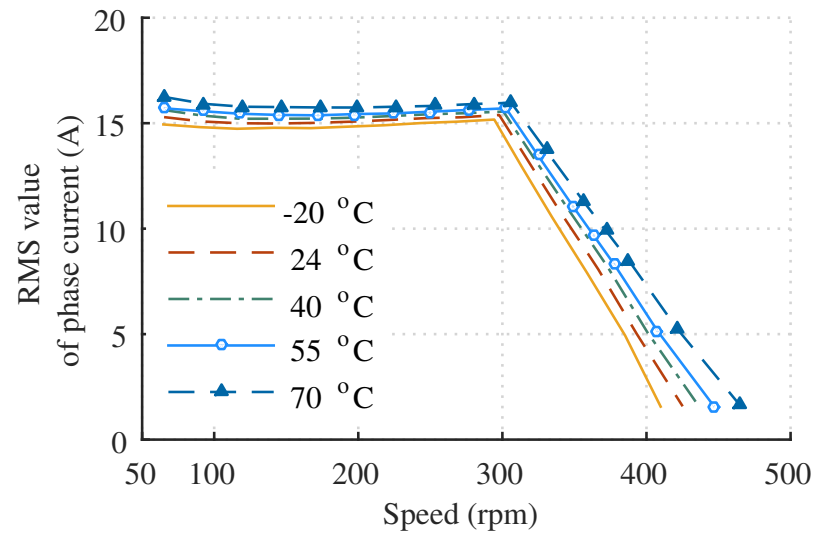

Fig. 10. The RMS value of phase current vs. speed curves of the ferrite magnet PMBLDC motor for different magnet temperatures

possible change in winding loss for the temperature range considered here is less than $10 \mathrm{~W}$. The core loss value of $35 \mathrm{~W}$ in rotor yoke and stator teeth is calculated by applying steinmetz equation to the flux density distribution obtained from FE model of the SAT PMBLDC motor.

The torque vs. speed characteristics of the designed motor obtained from the simulation of dynamic model are shown in Fig.9. It is found that the motor operation beyond the base speed varies considerably with the magnet temperature and the maximum motor speed for a given load torque decreases with colder magnets. Still, the presented design will meet the torque requirement for accelerating the vehicle to the maximum speed throughout the range of temperature considered in this study. The RMS value of the phase current of the machine plotted against speed of the motor is shown in Fig.10. The weakened magnet field due to drop in remanence at higher temperature implies a reduced back EMF, which results in higher current throughout the speed range considered. The increased current at higher temperature gives rise to higher copper losses and reduced efficiency as shown in Fig.11. This trend reverses beyond the base speed as the torque increases with temperature for a given speed. This results in higher output power and hence, an improved efficiency in spite of drawing more current. 


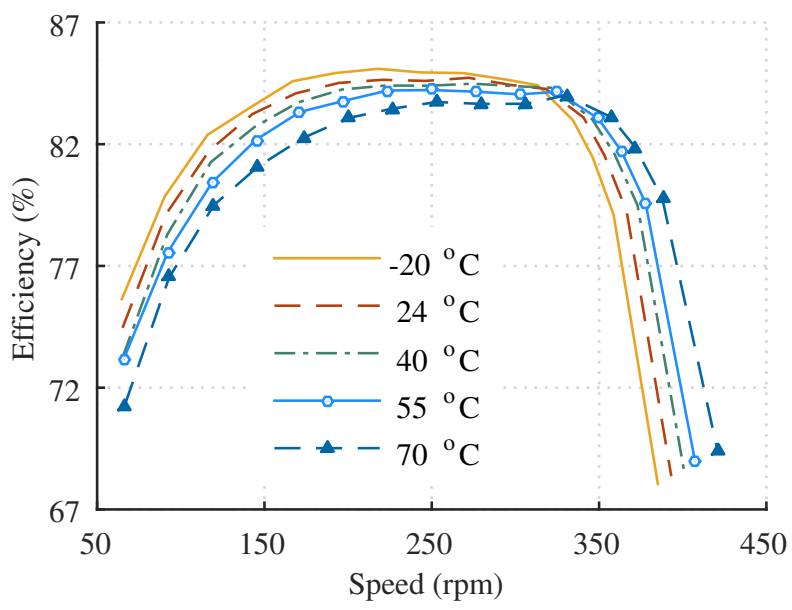

Fig. 11. The efficiency vs. speed curves of the ferrite magnet PMBLDC motor for different magnet temperatures

The impact of temperature dependence of ferrite magnet motor on system performance requires accurate modelling of power converters and controllers. The motor discussed is designed for a low cost powertrain of electric two-wheelers and in such applications closed loop controls are not usually implemented due cost constraints. Nevertheless, the presented study with consideration of the motor alone can give controller designers a better outlook into the performance variation with temperature beyond the base speed, which will be helpful in designing a control strategy for mitigating perceived speed changes to the user.

\section{CONCLUSION}

The interest in ferrite magnet machines appears to be increasing. As discussed in this study, the ferrite magnet machines are more susceptible to irreversible demagnetization due to armature reaction at lower temperature. Moreover, the ferrite magnet motor performance, especially beyond the constant torque operation varies considerably with magnet temperature. As the temperature of ferrite magnets drops, remanent flux density increases and knee point moves more towards the operating region of magnets in machines. From motor design perspective, as demonstrated in this study, designer has to ensure that the designed ferrite magnet motor is capable of delivering the specified torque throughout the operating speed, without any irreversible demagnetization of magnets.

The temperature dependant characteristics of ferrites have to be considered when designing ferrite magnet machines for applications such as electric powertrain where they are exposed to ambient temperature changes and field weakening operation spans across large operating speeds. This study is carried out on PMBLDC motor and can be extended to other type of ferrite magnet machines also.

\section{ACKNOWLEDGEMENT}

This research was supported by EU-FP7 NANOPYME Project (No. 310516) [30]. Authors would like to thank
Instituto de Magnetismo Aplicado (IMA), Spain for measuring the $\mathrm{BH}$ characteristics of magnets.

\section{REFERENCES}

[1] P. C. Dent and M. H. Walmer, "4.6: Supply chain sustainability rare earth materials," in 2010 IEEE International Vacuum Electronics Conference (IVEC). IEEE, May 2010, pp. 57-58.

[2] M. M. Rahman, K. T. Kim, and J. Hur, "Design and Optimization of Neodymium-Free SPOKE-Type Motor With Segmented Wing-Shaped PM," IEEE Transactions on Magnetics, vol. 50, no. 2, pp. 865-868, Feb. 2014.

[3] M. R. Mohammad, K.-T. Kim, and J. Hur, "Design and Analysis of a Spoke Type Motor With Segmented Pushing Permanent Magnet for Concentrating Air-Gap Flux Density," IEEE Transactions on Magnetics, vol. 49, no. 5, pp. 2397-2400, May 2013.

[4] H.-W. Kim, K.-T. Kim, Y.-S. Jo, and J. Hur, "Optimization Methods of Torque Density for Developing the Neodymium Free SPOKE-Type BLDC Motor," IEEE Transactions on Magnetics, vol. 49, no. 5, pp. 2173-2176, May 2013.

[5] P. Sekerak, V. Hrabovcova, J. Pyrhonen, L. Kalamen, P. Rafajdus, and M. Onufer, "Comparison of Synchronous Motors With Different Permanent Magnet and Winding Types," IEEE Transactions on Magnetics, vol. 49, no. 3, pp. 1256-1263, Mar. 2013.

[6] K. Sone, M. Takemoto, S. Ogasawara, K. Takezaki, and H. Akiyama, "A Ferrite PM In-Wheel Motor Without Rare Earth Materials for Electric City Commuters," IEEE Transactions on Magnetics, vol. 48, no. 11, pp. 2961-2964, Nov. 2012.

[7] K. Atallah and J. Wang, "A Rotor With Axially and Circumferentially Magnetized Permanent Magnets," IEEE Transactions on Magnetics, vol. 48, no. 11, pp. 3230-3233, Nov. 2012.

[8] D. G. Dorrell, M.-F. Hsieh, and A. M. Knight, "Alternative Rotor Designs for High Performance Brushless Permanent Magnet Machines for Hybrid Electric Vehicles," IEEE Transactions on Magnetics, vol. 48, no. 2, pp. 835-838, Feb. 2012.

[9] T. Sebastian, "Temperature effects on torque production and efficiency of PM motors using NdFeB magnets," IEEE Transactions on Industry Applications, vol. 31, no. 2, pp. 353-357, 1995.

[10] S. Ruoho and A. Arkkio, "Partial Demagnetization of Permanent Magnets in Electrical Machines Caused by an Inclined Field," IEEE Transactions on Magnetics, vol. 44, no. 7, pp. 1773-1778, Jul. 2008.

[11] S. Ruoho, J. Kolehmainen, J. Ikaheimo, and A. Arkkio, "Interdependence of Demagnetization, Loading, and Temperature Rise in a Permanent-Magnet Synchronous Motor," IEEE Transactions on Magnetics, vol. 46, no. 3, pp. 949-953, Mar. 2010.

[12] C. Kral, R. Sprangers, J. Waarma, A. Haumer, O. Winter, and E. Lomonova, "Modeling demagnetization effects in permanent magnet synchronous machines," in The XIX International Conference on Electrical Machines - ICEM 2010. IEEE, Sep. 2010, pp. 1-6.

[13] H.-s. Kim, Y.-M. You, and B.-i. Kwon, "Rotor Shape Optimization of Interior Permanent Magnet BLDC Motor According to Magnetization Direction," IEEE Transactions on Magnetics, vol. 49, no. 5, pp. 2193-2196, May 2013.

[14] S.-M. Jang, H.-J. Seo, Y.-S. Park, H.-I. Park, and J.-Y. Choi, "Design and Electromagnetic Field Characteristic Analysis of $1.5 \mathrm{~kW}$ Small Scale Wind Power Generator for Substitution of Nd-Fe-B to Ferrite Permanent Magnet," IEEE Transactions on Magnetics, vol. 48, no. 11, pp. 2933-2936, Nov. 2012.

[15] O. Craiu, N. Dan, and E. Badea, "Numerical analysis of permanent magnet DC motor performances," IEEE Transactions on Magnetics, vol. 31 , no. 6, pp. 3500-3502, 1995.

[16] I. Petrov, M. Polikarpova, and J. Pyrhonen, "Rotor surface ferrite magnet synchronous machine for generator use in a hybrid application Electro-magnetic and thermal analysis," in IECON 2013 - 39th Annual Conference of the IEEE Industrial Electronics Society. IEEE, Nov. 2013, pp. 3090-3095.

[17] C. Debruyne, M. Polikarpova, S. Derammelaere, P. Sergeant, J. Pyrhonen, J. J. M. Desmet, and L. Vandevelde, "Evaluation of the Efficiency of Line-Start Permanent-Magnet Machines as a Function of the Operating Temperature," IEEE Transactions on Industrial Electronics, vol. 61, no. 8, pp. 4443-4454, Aug. 2014.

[18] S. Minnich, M. Chari, and J. Berkery, "Operational Inductances of Turbine-Generators by the Finite-Element Method," IEEE Transactions on Power Apparatus and Systems, vol. PAS-102, no. 1, pp. 20-27, Jan. 1983. 
[19] T. Woolmer and M. McCulloch, "Analysis of the Yokeless And Segmented Armature Machine," in 2007 IEEE International Electric Machines \& Drives Conference, vol. 1. IEEE, May 2007, pp. 704-708.

[20] W. Fei, P. C. K. Luk, and K. Jinupun, "A new axial flux permanent magnet Segmented-Armature-Torus machine for in-wheel direct drive applications," in 2008 IEEE Power Electronics Specialists Conference. IEEE, Jun. 2008, pp. 2197-2202.

[21] F. Giulii Capponi, G. De Donato, and F. Caricchi, "Recent Advances in Axial-Flux Permanent-Magnet Machine Technology," IEEE Transactions on Industry Applications, vol. 48, no. 6, pp. 2190-2205, Nov. 2012.

[22] T. J. Woolmer and M. McCulloch, "Axial flux permanent magnet machines: a new topology for high performance applications," in IET Hybrid Vehicle Conference 2006, vol. 2006. Coventry, UK: IEE, 2006, pp. 27-42.

[23] S. M. Jafari-Shiadeh and M. Ardebili, "Analysis and comparison of axial-flux permanent-magnet brushless-DC machines with fractional-slot concentrated-windings," in 4th Annual International Power Electronics, Drive Systems and Technologies Conference. IEEE, Feb. 2013, pp. $72-77$.

[24] K.-C. Kim, S.-B. Lim, D.-H. Koo, and J. Lee, "The Shape Design of Permanent Magnet for Permanent Magnet Synchronous
Motor Considering Partial Demagnetization," IEEE Transactions on Magnetics, vol. 42, no. 10, pp. 3485-3487, Oct. 2006.

[25] T. Higashi, T. Miyoshi, R. Kato, M. Kono, M. Inoue, T. Nagumo, T. Fukui, K. Ohsaki, and M. Iwasaki, "Development of Rare Earthsaving Magnet Using Localized Diffusion Method," SAE Int. J. Alt. Power, vol. 2, no. 2, pp. 394-400, Apr. 2013.

[26] C. Chan, W. Xia, J. Jiang, K. Chan, and M. Zhu, "Permanent magnet brushless drives," IEEE Industry Applications Magazine, vol. 4, no. 6, pp. 16-22, 1998.

[27] K. Chau, C. Chan, and J. Jiang, "A new surface-inset, permanentmagnet, brushless DC motor drive for electric vehicles," IEEE Transactions on Magnetics, vol. 36, no. 5, pp. 3810-3818, 2000.

[28] O. Mohammed, S. Liu, and Z. Liu, "A phase variable model of brushless dc motors based on finite element analysis and its coupling with external circuits," IEEE Transactions on Magnetics, vol. 41, no. 5, pp. 1576-1579, May 2005

[29] M. Fazil and K. R. Rajagopal, "Nonlinear Dynamic Modeling of a Single-Phase Permanent-Magnet Brushless DC Motor Using 2-D Static Finite-Element Results," IEEE Transactions on Magnetics, vol. 47, no. 4, pp. 781-786, Apr. 2011

[30] "http://nanopyme-project.eu." 